ORIGINAL ARTICLE

\title{
Epidemiology, Diagnosis and Therapeutic Approaches of Cryptorchidism at the Panzi General Hospital, DR Congo: A 5-year Retrospective Study
}

\author{
Alumeti Munyali Désiré ${ }^{1,2}$, Cikwanine Buhendwa², Tetsatsi Momo Aimé \\ Césaire $^{1}$, Kavira Ise Somo Prisca ${ }^{2}$, Luhiriri Ndanda Levi ${ }^{2}$, Nanga Batende \\ David $^{2}$, Ahuka Ona Longombe ${ }^{2}$, Watcho Pierre ${ }^{1 *}$
}

\footnotetext{
OPEN ACCESS

Citation: Alumeti Munyali Désiré, Cikwanine Buhendwa, Tetsatsi Momo Aimé Césaire, Kavira Ise Somo Prisca, Luhiriri Ndanda Levi, Nanga Batende David, Ahuka Ona Longombe, Watcho Pierre. Epidemiology, Diagnosis and Therapeutic Approaches of Cryptorchidism at the Panzi General Hospital, DR Congo: A 5-year Retrospective Study. Ethiop J Health Sci.2020;30(1):107. doi:http:// dx.doi.org/ 10.4314/ejhs.v30i1.14

Received: May 25, 2019

Accepted: October 05, 2019

Published: January 1, 2020

Copyright: (C) 2020 Alumeti M.D. et al.

This is an open access article distributed under the terms of the Creative Commons Attribution License, which permits unrestricted use, distribution, and reproduction in any medium, provided the original author and source are credited.

Funding: Nil

Competing Interests: The authors declare that this manuscript was approved by all authors in its form and that no competing interest exists.

Affiliation and Correspondence:

${ }^{1}$ Research Unit of Animal Physiology and Phytopharmacology (URPAP),

Faculty of Science, University of

Dschang, Cameroon.

${ }^{2}$ School of Medicine and Community Health, Evangelical University in Africa, DR Congo

*Email: pierre.watcho@univdschang.org

/pwatcho@yahoo.fr
}

\section{ABSTRACT}

BACKGROUND: Cryptorchidism is a common congenital malformation characterized by unilateral or bilateral undescended testis in the scrotum. It is a common disease in pediatric urology although the prevalence is yet to be determined in the East DR Congo. The aim of this study was to describe the prevalence, clinical and therapeutic features of cryptorchidism at the Panzi General Hospital.

METHODS: Medical records of patients who underwent pediatric surgery between January 2011 and December 2016 were reviewed. The prevalence of cryptorchidism, associated malformations, sociodemographic features of patients and therapeutic protocols were examined. Collected data were analyzed using SPSS software.

RESULTS: A total of 5066 children were received during the study period in the service, of which 76 suffered from cryptorchidism giving a prevalence of $1.50 \%$ and an annual incidence of 12.70 . Unilateral cases were found in 53(69.74\%) patients among which $66.04 \%$ and $33.96 \%$ had unilateral right and left cryptorchidism respectively. Cryptorchidism was associated with other malformations in $71.1 \%$ of patients. The age of patients ranged from 0 to 15 years and $78.9 \%$ were older than two years. Surgery was the only therapeutic approach and fixation of cryptorchid testis in dartos through inguinal incision was the preferred therapeutic used method.

CONCLUSION: This study indicates that cryptorchidism is a relatively common and neglected disease in the Est-DR Congo, due to late consultation. Therefore, the local population and pediatricians should be sensitized on scrotal palpation techniques in order to shorten the consultation delay and prevent testis damages.

KEYWORDS: Cryptorchidism, epidemiology, diagnosis, fixation in dartos, Panzi General Hospital 


\section{INTRODUCTION}

Described for the first time by John Hunter in $1786(1,2)$, cryptorchidism is a common congenital malformation of the male genital tract (1-3). It is characterized by the absence of one (unilateral cryptorchidism) or both (bilateral cryptorchidism) gonads in the scrotum. Unlike other testicular malformations, undescended testis is generally found on the normal migration course $(2,4,5)$. Cryptorchidism is more frequent in premature delivery with about $30 \%$ affected annually worldwide. An estimated 3 to $5 \%$ of fullterm newborn babies are victims of cryptorchidism with predominance of the unilateral form (6-9). In DR Congo, studies at the national level are yet to be done, but Tshitala and coworkers reported an annual prevalence of 6.5 cases per year in Kinshasa (10).

The diagnosis of cryptorchidism is primarily based on scrotum palpation and is ascertained in the presence of permanent or transient scrotal emptiness $(11,12)$. Non-palpable testes may fall into one of the following categories: intraabdominal location, agenesis, or inguinal location caused by dysplasia or atrophy. Palpable undescended testes are located along the inguinoscrotal region $(4,11,13)$. In order to preserve the chances of procreation, the management of cryptorchidism should be performed as soon as possible. Evidence form the literature indicates that intra-abdominal hyperthermia can generate oxidative stress which is responsible for testis damages $(5,14,15)$. For instance, azoospermia is evident in $13 \%$ of unilateral cryptorchidism and increases to $89 \%$ in untreated bilateral cryptorchid patients. Approximately, $10 \%$ of infertile men have a history of cryptorchidism and orchidopexy. There are two therapeutic approaches of cryptorchidism: hormonal and surgical treatment. Hormonal treatment with human chorionic gonadotropin (hCG) or gonadotropin-releasing hormone $(\mathrm{GnRH})$ may be initially administered $(3,16,17)$. The theoretical basis for hormonal treatment is the stimulation of Leydig cells to produce testosterone, inducing inguinal-scrotal testicular descent $(6,17)$. However, this approach is less effective and generates serious adverse effects, the reason why surgery is preferred $(6,15,18)$.
Orchidopexy through inguinal operation or laparoscopy is the standard definitive treatment for palpable or non-palpable cryptorchidism. Orchidopexy is commonly performed before 2 years of age, and increasing research suggests that a surgery before 1 year of age may normalize spermatogenesis by preventing the degenerative changes of the testes and germ cell loss. Late diagnostic and treatment of cryptorchidism may lead to infertility and testicular cancer $(8,18,19)$. Because of poverty, populations of the East DR Congo mainly rely on medicinal plants for primary healthcare leading therefore to late consultation. In order to sensitize local population from SouthKivu, this pilot study was designed to determine the prevalence of cryptorchidism at the Panzi General Hospital, focusing on the epidemiological, clinical and therapeutic aspects in childhood.

\section{MATERIALS AND METHODS}

Study design: It was a 5 years retrospective and observational study performed at the pediatric Surgery Department of the Panzi General Hospital, South-Kivu, DR Congo. Data concerning epidemiological, clinical and therapeutic characteristics were collected in the hospital records, the anesthesia cards and the surgery protocol registers of patients received from the $1^{\text {st }}$ January 2011 to $31^{\text {st }}$ December 2016.

Inclusion and exclusion criteria: Male patients who underwent surgery due to cryptorchidism at the Department of Pediatric Surgery were included in this study. Patients suffering from any problem other than cryptorchidism as well as those with incomplete files were excluded from the study.

Data collection and management: From all cryptorchidism files, the epidemiological (prevalence of cryptorchidism, date of consultation, age of patient and scrotal vacuity identifier), clinical (clinical presentation-unilateral or bilateral cryptorchidism- and associated malformations) and therapeutic parameters [surgical approach, testis description (localization and physical aspect, performed gesture, hospitalization period and postoperative course)] were collected.

Data analysis: From the collected data, the intrahospital prevalence of cryptorchidism was estimated. Clinical and therapeutic aspects were also evaluated using SPSS 2.0 software. 
Ethical authorization: This study was performed in accordance with the ethical authorization $\mathrm{N}^{\circ}$ CNES001/DPSK/114PP/2018 delivered on March $16^{\text {th }} 2018$ by the National Health Ethic Committee, DR Congo.

\section{RESULTS}

EPIDEMIOLOGICAL ASPECT: From January 2011 to December 2016, 5066 (Five thousand sixty-six) children underwent surgery for different ailments among which seventy-six children were suffering from cryptorchidism, giving an intrahospital prevalence of $1.5 \%$ with an annual frequency of 12.7 cases.

Age at the time of diagnosis: The age of patients included in this study ranged from 7 days to 15 years with an average of $5.7 \pm 4.6$ years. Sixty cryptorchid children $(78.9 \%)$ were over 2 years old, and among them $26.3 \%$ were over 8 years old (Table 1). Scrotal vacuity was detected by the mother in $85.5 \%$ of cases while $6.6 \%$ was selfexamination (Table 1).

Table 1: Epidemiological and clinical aspects of cryptorchidism at the Panzi General Hospital

\begin{tabular}{|c|c|c|}
\hline Variables & Frequency (n) & Percentage (\%) \\
\hline \multicolumn{3}{|l|}{ Age in years $(n=76)$} \\
\hline $0-2$ & 16 & 21.05 \\
\hline $2-5$ & 28 & 36.84 \\
\hline $5-8$ & 12 & 15.79 \\
\hline $8-11$ & 12 & 15.79 \\
\hline $11-15$ & 08 & 10.53 \\
\hline \multicolumn{3}{|l|}{ Reason for consultation $(n=76)$} \\
\hline Scrotal emptiness & 74 & 97.37 \\
\hline Permanent scrotal emptiness & 62 & 83.78 \\
\hline Transient scrotal emptiness & 12 & 16.22 \\
\hline Scrotal swelling & 01 & 1.32 \\
\hline Recurrence after surgery & 01 & 1.32 \\
\hline \multicolumn{3}{|c|}{ Who suspected the problem? $(n=76)$} \\
\hline Mother & 65 & 85.53 \\
\hline Child himself & 05 & 6.59 \\
\hline Nurse & 04 & 5.26 \\
\hline Doctor & 02 & 2.63 \\
\hline \multicolumn{3}{|l|}{ Diagnosis method $(n=96)$} \\
\hline Scrotal palpation & 76 & 100.0 \\
\hline Ultrasound & 20 & 26.32 \\
\hline \multicolumn{3}{|l|}{ Type of cryptorchidism $(n=76)$} \\
\hline Bilateral & 23 & 30.26 \\
\hline Unilateral & 53 & 69.74 \\
\hline - Right & 35 & 66.04 \\
\hline - Left & 18 & 33.96 \\
\hline
\end{tabular}

\section{CLINICAL ASPECT}

Types of cryptorchidism: Scrotal emptiness was the primary $(97.37 \%)$ reason for consultation and was permanent in 62(83.78\%) patients while transient emptiness was found in $12(16.22 \%)$ patients. Ultrasonography was performed in 20 cases $(26.32 \%)$. One patient $(1.32 \%)$ declared painful cryptorchidism associated with twisting spermatic cord and another one $(1.32 \%)$ came for a second surgery (failure of the first attempt). From the total, 23(30.26\%) patients had bilateral cryptorchidism while 53(69.74\%) had unilateral cryptorchidism, among which the right size was affected in 35(66.04\%) cases against $18(33.96 \%)$ for the left size (Table 1). The testis was palpable 
in 21 children $(27.63 \%)$ and non-palpable in 55 children $(72.37 \%)$.

Associated malformations: Cryptorchidism was associated with other malformations including the persistence of the peritoneal-vaginal canal in 45 cases $(83.33 \%)$, umbilical hernia in 4 children $(7.41 \%)$ and hypospadias in $3.70 \%$ of the children (Table 2).

Table 2: Malformations associated to cryptorchidism at the Panzi General Hospital

\begin{tabular}{lll}
\hline Associated malformations $(\mathbf{n = 5 4 )}$ & Frequency (n) & Percentage (\%) \\
\hline Persistence of peritoneal-vaginal canal & 45 & 83.33 \\
Umbilical hernia & 04 & 7.41 \\
Hypospadias & 02 & 3.70 \\
Beckwith-Wiedemann Syndrome & 01 & 1.85 \\
Phimosis & 01 & 1.85 \\
Prune Belly Syndrome & 01 & 1.85 \\
Total & $\mathbf{5 4}$ & $\mathbf{7 1 . 1}$ \\
\hline
\end{tabular}

Therapeutic and post-operative aspects: Seven patients (9.21\%) reported Pregnyl administration (intramuscular injection) once a week for four weeks before surgical approach (Table 3). The average age at surgery was $5.8 \pm 4.5$ years. After pre-anesthetic consultation, surgical treatment was the only therapeutic approach $(100 \%)$ and was inguinal in $75(98.68 \%)$ patients or scrotal surgery in one $(1.32 \%)$ case. The testis was located deep in the inguinal orifice in $68.4 \%$ of patients. During intervention, testis was fixed "in dartos" in one time in 72 children $(94.74 \%)$, or in two stages according to Fowler-Stephens method in one patient $(1.32 \%)$ who presented a Prune Belly syndrome with a short spermatic cord. This patient had unilateral right cryptorchidism, and six months after the first intervention, a second surgery was performed to fix in dartos the testis which was viable but atrophied. Unilateral orchiectomy with contralateral testicular fixation was performed in three $(4.95 \%)$ cases (Table 3 ).

Severe testicular atrophy was detected in two patients $(2.6 \%)$. No extemporaneous biopsy or histochemical tests were performed before orchidopexy or before orchidectomy. Hospitalization period ranged from 1 to 4 days with an average of $2.3 \pm 1.8$ days. Four patients $(5.3 \%)$ had complications including three cases of scrotal hematoma $(75 \%)$ and a case of testicular atrophy (25\%) leading secondarily to orchidectomy. The mean follow-up period was three years, the cosmetic aspect of the scrotal region was generally normal although two patients had asymmetric scrotal presentation following unilateral orchiectomy.

\section{DISCUSSION}

The prevalence of cryptorchidism varies from 3 to $5 \%$ in full-term newborns and around $30 \%$ in preterm neonates. It is estimated that around 0.8 to $1 \%$ of one-year old children suffer from cryptorchidism $(3,11,20)$. In this study, out of 5066 patients who were received at the pediatric urology service, 76 had cryptorchidism while 158 children were suffering from inguinal hernia, and 37 cases were recorded for congenital hydrocele. The intrahospital prevalence $(1.5 \%)$ recorded in this study is similar to the results found by Gueye and coworkers (21) and Sano and collaborators (22) who found $1.41 \%$ and $1.2 \%$ in Senegal and Ouagadougou respectively. The annual frequency of cryptorchidism varies according to studies $(10,23)$. In this series, we found an average of 12.6 cases per year. This prevalence is similar to that of Ndour and collaborators in Dakar (15.37 cases) (11) and greater than those of Tshitala and coworkers (10) and Mouafo and collaborators (7) who recorded 6.5 and 8.3 cases per year in Kinshasa and Yaoundé respectively. 
Table 3: Therapeutic approaches of Cryptorchidism at the Panzi General Hospital.

\begin{tabular}{lll}
\hline Variable & Frequency (n) & Percentage (\%) \\
\hline Treatment approach (n=76) & 00 & 0 \\
Pregnyl without surgery (500 IU) & 07 & 9.21 \\
Pregnyl before surgery & 69 & 90.79 \\
Surgery without Pregnyl & & \\
Surgical technic (n=76) & 75 & 98.68 \\
Inguinal incision & 01 & 1.32 \\
Scrotal incision & & \\
Testis location (76) & 52 & 68.42 \\
Deep inguinal orifice & 10 & 13.16 \\
Superficial inguinal orifice & 10 & 13.16 \\
Abdominal & 04 & 5.26 \\
Out of the way & & \\
Spermatic cord length (76) & 70 & 92.11 \\
Long & 06 & 7.89 \\
Short & & \\
Appearance of the testis (76) & 46 & 60.53 \\
Eutrophic & 30 & 39.47 \\
Atrophic & & \\
Treatment options (76) & 72 & 94.74 \\
Lowering in one time & 01 & 1.32 \\
Lowering in two stages (Fowler-Stephens) & 03 & 4.95 \\
Unilateral orchiectomy & 00 & 0 \\
Bilateral orchiectomy &
\end{tabular}

Cryptorchidism is primarily found in newborn babies and should be treated during the first two years of life. The average patient age at diagnosis in the present series was $5.7 \pm 4.6$ years with $78.9 \%$ patients older than the recommended two years. These data suggest a preoccupying delay of consultation exposing patients to severe damages. In the African context, and especially in DR Congo, the delayed diagnosis could be consecutive to the absence of epidemiological supervision of congenital pathologies. Moreover, regardless of the taboo on sex related illnesses, African populations deeply rely on alternative medicine for health problems. In fact, Balagizi and collaborators and Mwangamwanga and collaborators reported that poverty and armed conflicts, which are permanent in the eastern province of the Democratic Republic of Congo, limit the accessibility of health structures $(24,25)$. These factors could explain the recorded delay of consultation as in other African regions.
The average age of children was lower compared to the African nine years old value (10). To prevent complications due to delayed management of cryptorchidism, Ritzén and collaborators suggested a monthly visit to newborn babies for cryptorchidism diagnosis in order to prevent late diagnosis and further risk factors including infertility and testicular cancer (18).

In this study, $97.37 \%$ of patients consulted for scrotal vacuity which is the main characteristic of cryptorchidism $(11,23,26)$. Data from the literature indicates that unilateral cryptorchidism is more prevalent among patients with the dominance of the right or left side varying from one study to another (1,7-9). In this work, right unilateral cryptorchidism (66.04\%) was more prevalent, which contrasts the results of Bouya and collaborators who found the left unilateral cryptorchidism in $53.98 \%$ of patients (27). Our data are similar to those of Ndour and coworkers 
(11) and Gruner and collaborators (26) who respectively found a right unilateral cryptorchidism in $62 \%$ and $68 \%$ of patients.

Cryptorchidism is generally associated with other genital malformations. In our series, $71.1 \%$ presented at least one congenital malformation. Persistence of the peritoneal-vaginal canal was the most prevalent malformation $(83.33 \%)$. These data matched the view of many authors and suggest that in case of cryptorchidism, the external genital tract should be explored in order to diagnose and solve any other associated malformation $(5,10,16)$.

Results of this study indicate that surgery was performed as soon as cryptorchidism was diagnosed. This observation is in accordance with the Nordic consensus on the treatment of cryptorchidism which recommends a surgical treatment between 6 and 12 months of life to prevent testicular exposure to oxidative stress due to the high abdominal temperature $(3,18)$. Surgery is the best treatment approach for cryptorchidism, and the predominance of inguinal surgery is consecutive to the absence of laparoscopic equipment in the Panzi General Hospital. In the African series, the inguinal approach remains the main pathway with fixation of the testis in dartos $(10,20,21)$, the pediatric coelioscopy being inaccessible in many health services $(4,11,27)$. This method is the easiest and helps identify the testis position, the length of the cord, the testis appearance; testis lowering is simple after ligation of the peritoneal-vaginal canal $(4,11,29,30)$. No major post-operative signs of complications were noted in patients, therefore indicating the mastery of the technique.

In conclusion, cryptorchidism is a common congenital pathology in pediatric surgery. This study revealed a prevalence of $1.5 \%$ at the Panzi General Hospital with an annual incidence of 12.7. Patients were generally older than the recommended value. In the African context, insufficient health centers and poverty limit early consultation exposing cryptorchid patients to infertility and testis cancer risks. Therefore, sensitization should be made not only to the population, but also to the pediatric care giver for systematic scrotal palpation for early diagnosis and treatment of babies with scrotal vacuity. Patients treated for cryptorchidism should also be followed to evaluate their fertility.

\section{ACKNOWLEDGEMENTS}

The authors would like to thank "Brot (Pain Pour le Monde)" for financial support. We would also like to thank the medical, nurses, operating theater of the Pediatric Surgery Service of Panzi General Hospital, the medical student of School of Medicine and Community Health, Evangelical University in Africa, who assisted in data collection. We are grateful to colleagues of the Research Unit of Animal Physiology and Phytopharmacology (URPAP), Faculty of Sciences, University of Dschang, Cameroon.

\section{REFERENCES}

1. Leslie DT, Sutchin RP, Anthony AC. A history of cryptorchidism: Lessons from the eighteenth centry. J Pediatr Urol. 2007;3 :426-432.

2. Goel P, Rawat JD, Wakhlu A, Kureel SN. Undescended testicle: an update on fertility in cryptorchid men. Indian $J$ Med Res 2015; 141:163-171.

3. Rod J, Marret JB, Dupont C, Ravasse P. Prise en charge chirurgicale des testicules non descendus entre 6 et 12 mois : un message long à transmettre. Arch Pediatr 2016 ; 23(5):477480.

4. Averous M et Lopez C. La cryptorchidie : le point de vue de l'urologue pédiatre. Gynécol Obstet Fertil 2004; 32(9) :813-817.

5. Robin G, Boitreille F, Marcelli F, Collin P, Leroy M, Mitchell V, Dewailly D, Rigot M. La cryptorchidie : de physiopathologie à l'infertilité. Gynécol Obstet Fertil 2010 ;38: 588-599.

6. Schumacher M, Seeger M, Szavay P. Rôle de la laparoscopie dans la cryptorchidie. Forum Med Suisse 2014 ;7(14):122-126.

7. Mouafo Tambo FF, Salihou AS, Fossi KG, Kouna TIN, Lyhmi NS, Ndongo R, Ze Minkandé J, Andze OG, Sosso MA. Prise en charge du testicule non descendu chez l'enfant a yaounde: a propos de 71 cas. Mali Médical 2017 ; 32(3):20-22.

8. Penson F, Krishnaswami S, Jules A, Seroogy C, Pheeters ML. Effectiveness of hormonal and 
surgical therapies for cryptorchidism: a systematic review. Pediatrics 2013;131(6):e1897-e1907.

9. Sapin E. Ectopie testiculaire et cryptorchidie; de quoi parle-t-on? Indications opératoires. Arch Pediatr 2013 ; 21(1) :113-117.

10. Tshitala B, Tshipeta A, Mputu Y, Lufuma LN. Notre expérience dans le traitement des cryptorchidies aux cliniques universitaires de Kinshasa. Med Afr Noire 1993 ; 40:108-111.

11. Ndour O, Fall M, Faye Fall AL, Diouf C, Ndoye NA, Ngom G, Ndoye M. Aspects épidémiologiques, cliniques et thérapeutiques de la cryptorchidie chez l'enfant: analyse de 123 observations. Afr J Urol. 2015;21:10-14.

12. Gueye SM, Ba M, Ndoye A, Sylla C, Fall PA, Mensah A. La cryptorchidie chez l'enfant sénégalais en âge scolaire. Andrologie 1996;6:287-92.

13. Mustapha I, Serap B., Nese K, Haluk S. (2012). Oxydative, inflammatory and immunologic status in children with undescended testes. Pediatr. Int 2012;54: 816919.

14. Chevalier N, Brucker-Davis F, Lahlou N, Coquillard P, Pugeat M, Pacini P, PanaïaFerrari P, Wagner-Mahler K, Fénichel P. A negative correlation between insulin-like peptide 3 and bisphenol A in human cord blood suggests an effect of endocrine disruptors on testicular descent during fetal development. Hum Reprod 2015;30 (2): 447-453.

15. Hudson M, Southwell B, Li R, Ismail K, Harisis $G$, Chen N. The regulation of testicular descent and the effects of cryptorchidism. Endocr. Rev 2013; 34: 725-752.

16. Merrot T. Prise en charge des testicules non descendus. Prog Urol 2009; 19: 265-8.

17. Merrot T. Prise en charge des testicules non descendus. Prog Urol 2009; 19: 265-8.

18. Ben Dhaou, Zouari M, Zitouni H, Jallouli M, Mhiri R. Traitement chirurgical de la cryptorchidie chez l'enfant: Comparaison des voies d'abord scrotale (Bianchi) et inguinale. Prog Urol 2015. 25:598-602.

19. Ritzén EM, Bergh A, Bjerkens R, Christiansen $\mathrm{P}$, Corrtes D, Haugen SE et al. Nordic consensus on treatment of undescended testes. Acta Paediatr 2007;96:638-643.

20. Jallouli M, Mefteh S, Rebai T, Mhiri R. Cryptrchidie : influence sur la fértilité de l'âge au moment de l'orchidopexie, du siège et de la taille du testicule et de l'existence d'anomalies épididymaires. Androl 2010 ; 20 :243-246.

21. Kollin C, Karpe B, Hesser U et al. Surgical treatment of unilatérally undescended testes: testicular growth after randomization to orchiopexy at age 9-month or 3-year. $J$ Urol 2007 ; 178 :1589-1593.

22. Gueye SM, Ba M, Sylla C, Deme ML, Diagne BA, Mensah A. L'orchidopexie " in dartos » dans le traitement de la cryptorchidie. J Chir 1992;129:263-5.

23. Sano D, Wandaogo A, Tapsoba TL, Sanou A. Les anomalies de position du testicule: enquête épidémiologique en milieu scolaire à Ouagadougou. Med Afr Noire 1999;46(2):757.

24. Qarro A, Ammani A, Basine K, Najoui M, Samir J. La Cryptorchidie : Physiopathologie et prise en charge. Rev. Méd. Gd. Lacs $2013 ; 5$ (3): $34-42$.

25. Balagizi K.I., Mirindi A.T., Mushagalusa T.B., Nabino V.B., Koh K., Kim S.H.The cultivation of wild food and medicinal plants for improving community livelihood: The case of the Buhozi site, DR Congo. Nutr Res and Pract 2013; 7(6): 510-518.

26. Mwangamwanga I., Balagizi K., Wabika D., Mapenzi A., Iragi K., Nyakabasa M., Ntamwira N. (2013). Contribution à l'étude floristique des jachères post-culturales du groupement de Ciriri, Burhinyi, Territoire de Mwenga. Cahiers du CERUKI 2013; 44 :78112.

27. Hensel KO, Caspers T, Jenke AC, Shuler E, Wirth S. Operative management of cryptorchidism: guilines and reality a 10-year observational analysis of 3587 cases. $B M C$ Pediatrics 2015;15: 116 -205.

28. Bouya PA, Odzébé AWS, Avala PP, Ondongo AM, Koutaba E, Mbika AIC. Prise en charge de la cryptorchidie au centre hospitalier et universitaire de Brazzaville. Basic Clin. Androl $2012 ; 22: 108-111$. 
29. Gruner M, Crapin C, Audry G, Larroquet M, Scheye T. Cryptorchidie, ectopie testiculaire. Encycl. Méd. Chir. Pediatr 1992 ; 4-089 :1-7.

30. Bey E, Gaget O, Jund J, Overs C, Skowron O. Cryptorchidie: la présence d'un canal péritonéo-vaginal permeable devrait-elle influer dans le choix de la technique chirurgicale ? Prog urol 2016; 26 :1185-1190.

31. Biserte J. Chirurgie du testicule non descendu. Encycl Med Chir 2001;41-410:1-11. 